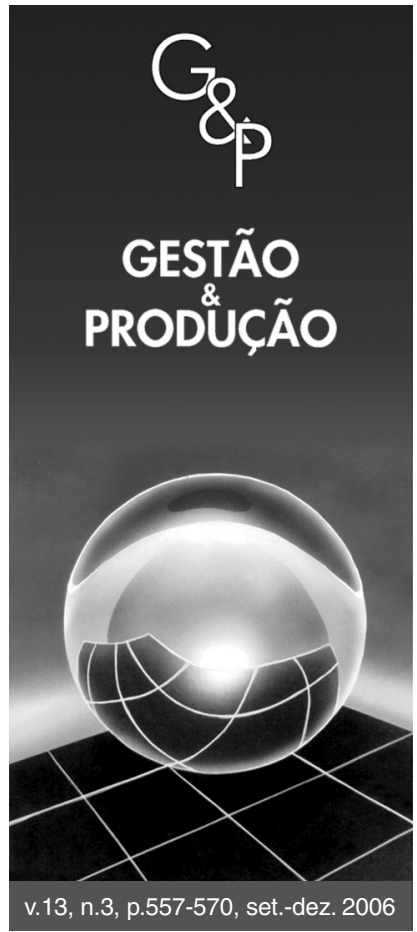

\section{MEDIÇÃO DE DESEMPENHO AMBIENTAL BASEADA EM MÉTODO MULTICRITERIAL DE APOIO À DECISÃO: ESTUDO DE CASO NA INDÚSTRIA AUTOMOTIVA}

\author{
Sheila Oliveira de Castro da Luz \\ Programa de Pós-Graduação em Engenharia de Energia, Ambiente e Materiais, \\ Universidade Luterana do Brasil - ULBRA, \\ Av. Farroupilha, 8001, CEP 92425-900, Canoas, RS, Brasil, \\ e-mail: sheilacastrodaluz@yahoo.com.br \\ Miguel Afonso Sellitto
} Programa de Pós-Graduação em Engenharia de Produção e Sistemas - PPGEPS, Universidade do Vale do Rio dos Sinos - UNISINOS, Av. Unisinos, 950, CEP 93022-000, São Leopoldo, RS, Brasil, e-mail: sellitto@unisinos.br

Luciana Paulo Gomes

Programa de Pós-Graduação em Engenharia Civil - PPGEC, Universidade do Vale do Rio dos Sinos - UNISINOS, Av. Unisinos, 950, CEP 93022-000, São Leopoldo, RS, Brasil, e-mail: lugomes@unisinos.br

Recebido em 26/6/2006 Aceito em 04/10/2006

\title{
Resumo
}

Este artigo apresenta e discute um estudo de caso sobre medição de desempenho ambiental (MDA) baseada em um método multicriterial de apoio à decisão, o AHP. A medição foi feita em uma operação de manufatura da indústria automotiva, cujo Sistema de Gestão Ambiental (SGA) é certificado conforme a norma ISO 14001:2004. A metodologia foi desenvolvida de forma a viabilizar a sua extensão a outras indústrias ou tipos de operação. $O$ artigo inicia apresentando uma discussão sobre desempenho empresarial e ambiental, justificando a necessidade de um índice para medir e comunicar este desempenho. Cita-se o método multicriterial usado e, a seguir, propõe-se a metodologia de medição, na qual se formulam construtos de sustentação do índice, calculam-se importâncias relativas dos construtos e especificam-se os indicadores. $O$ índice foi calculado para o desempenho atual, chegando-se a um desempenho ambiental próximo a $85 \%$ do máximo possível. Os construtos empregados na medição são: resíduos sólidos; efluentes; emissões atmosféricas; uso de recursos naturais; e gestão ambiental. As principais oportunidades de melhoria ambiental são reduções no uso de recursos naturais e em emissões atmosféricas.

Palavras-chave: medição do desempenho ambiental, controle do desempenho ambiental, indicadores ambientais, estratégia ambiental, modelagem de desempenho ambiental.

\section{Introdução}

A preocupação formal com o meio ambiente é recente na história da humanidade, tendo se manifestado mais a partir dos anos 1960. Alguns encontros mundiais foram realizados desde então, indicando o interesse pelo tema. Em 1972, foi realizada uma conferência mundial sobre Meio Ambiente, em Estocolmo. Em 1992, foi realizada a ECO-92, no Rio de Janeiro, promovida pela UNCED (United Nations Conference on Environment and Development). Nesta reunião, foi elaborada a Agenda 21, que passou a ser opção de referência na implantação de programas e políticas de preservação do meio ambiente e desenvolvimento sustentável. Outros dois encontros de importância ocorreram em Kioto, em 1998, no qual se discutiu o impacto das emissões gasosas ao meio ambiente, e em Johannesburgo (Rio mais dez), em 2002, a conferência das Nações Unidas sobre ambiente e 
desenvolvimento sustentável (Machado, 1997; Monteiro et al., 2003).

Como pressões legais e públicas têm crescido neste tema, a necessidade de medição do desempenho ambiental tem sido mais discutida em estratégias funcionais de manufatura. Segundo Donaire (1999), organizações de manufatura costumam responder a pressões ambientais com: i) controles do tipo fim-de-tubo, instalando dispositivos que neutralizam os ataques ambientais, mas não interferem no processamento; ii) controles em processo, reprojetados para reduzir as pressões ambientais, reaproveitar materiais e racionalizar insumos energéticos; ou iii) incorporando à missão da empresa um desempenho ambiental elevado, geralmente por pressão do mercado consumidor, tão fiscalizador quanto os agentes legais.

Uma forma que organizações usam para responder a tais pressões é a implantação de SGA (sistemas de gerenciamento ambiental), os quais, entre outros requisitos, exigem indicadores ambientais quantitativos. Indicadores quantitativos não são a expressão da realidade, mas um modelo empírico dela, de mais fácil comunicação, que torna pública e simples a informação sobre um assunto complexo ou uma tendência ainda não detectada.

Indicadores ambientais podem capturar dados complexos, de várias origens e segundo diversos modos de mensuração, e transformá-los em uma estrutura fácil de comunicar, tal como um índice global. Índices globais são o topo de uma pirâmide informacional, em cuja base estão os dados primários de campo, de várias naturezas, e, no meio, estão os indicadores que os capturam e comunicam acerca do complexo objeto estudado, o desempenho ambiental (Hammond et al., 1995).

Melo e Pegado (2006) citam, entre outras, algumas vantagens de se ter uma medição formal por indicadores quantitativos: i) síntese e comunicação da complexa informação exigida para a gestão de sistemas ambientais; ii) identificação de prioridades de ação; e iii) medição das lacunas, a diferença entre o desempenho atual e as metas. Pegado et al. (2001) observam duas lacunas em sistemas de medição: indicadores exclusivos são pouco úteis na análise do efeito ambiental de cadeias produtivas; e alguns sistemas de medição dão mais importância a indicadores de eficiência na gestão interna do que aos efeitos ambientais causados ou não evitados pela gestão. Kuhre (1998 apud Melo e Pegado, 2006) afirma que a medição evolutiva do desempenho ambiental permite melhorar os resultados da gestão ambiental, com ou sem um sistema formal de gestão.

A medição de desempenho ambiental surge na literatura em diversas fontes, das quais são citadas aquelas que foram úteis ao longo desta pesquisa. Tyteca (1996) define indicadores e compara desempenhos ambientais de operações; Zobel et al. (2002) fazem avaliações am- bientais em uma perspectiva de gestão do ciclo de vida de materiais; Azzone e Manzini (1994) medem o desempenho de uma estratégia de desenvolvimento ambiental; Thoresen (1999) propõe uma metodologia para a medição de desempenho ambiental; Ammenberg et al. (2002) usam sistemas de gerenciamento ambiental para criar melhorias e mensurar desempenho ambiental; Dias-Sardinha e Reijnders (2001 e 2005), em um primeiro momento, estruturam os conceitos de uma estratégia de gestão ambiental e uma conseqüente estrutura de medição de desempenho da estratégia e, em um segundo momento, usam a estrutura conceitual do BSC para criar um sistema de medição de desempenho de fatores ambientais e sociais relacionados à atividade empresarial; Campos (2001) apresenta o SGADA - Sistema de Gestão e Avaliação de Desempenho Ambiental -, um modelo que usa o BSC em um SGA para avaliar o desempenho ambiental de uma organização; Rossetto (2003) apresenta o Sistema Integrado de Gestão do Ambiente Urbano (SIGAU), um modelo baseado no BSC e em MCDA (Metodologias Multicritérios de Apoio à Decisão), que define fatores críticos em gestão urbana, incorporando indicadores sociais, ambientais, físico-espaciais e econômicos, em uma estrutura multinível de avaliação; Ramos e Melo (2006) usam avaliações por questionário de aspectos ambientais e chegam a um índice agregado para o desempenho ambiental de uma corporação; Banai-Kashani (1989) e Mazari-Hiriart (2006) usam o método AHP e Chiou e Tzeng (2002) e Gough e Ward (1996) usam outros métodos multicriteriais para apoio a decisões estratégicas em gerenciamento ambiental; Cornforth (1999) propõe uma metodologia para selecionar indicadores em uma dimensão, o uso do solo; e Pegado et al. (2001) e Melo e Pegado (2006) apresentam o Ecoblock, uma metodologia para medição de desempenho ambiental multidimensional.

O objetivo deste trabalho é apresentar um método de medição de desempenho ambiental, que calcula um índice global entre 0 e $100 \%$, específico para uma operação, mas que pode ser comparado com outras operações, dentro e fora da indústria e, cumulativamente, em cadeias produtivas. Para exemplificar o método e robustecer os procedimentos, este foi aplicado em uma operação de manufatura da indústria automobilística. Usaram-se medições objetivas de grandezas e julgamentos acerca de seu desempenho [ótimo; bom; médio; ruim; péssimo]. Após a introdução, o restante do artigo está estruturado da seguinte forma: i) revisão teórica sobre medição de desempenho empresarial, desempenho ambiental e o método multicriterial utilizado, o $A H P$; ii) metodologia de pesquisa e resultados de aplicação; iii) discussão e contribuição do caso; e iv) conclusões e sugestões de continuidade. São delimitações de pesquisa: i) um único estudo 
de caso em manufatura do setor automobilístico; e ii) uso exclusivo do $A H P$ como apoio à decisão.

\section{Medição de desempenho empresarial}

Medições de desempenho são essenciais na atividade empresarial e os métodos usados em tais medições têm despertado interesse entre pesquisadores e praticantes. Bititci et al. (2002), Gomes et al. (2004) e Melnick et al. (2004) apresentam resenhas parciais de estruturas e métodos já propostos. Pires (2004) define desempenho como a informação quantificada do resultado obtido em processos, que pode ser comparada com metas, padrões, resultados passados e de outros processos. O desempenho empresarial desperta dois interesses distintos. O primeiro diz respeito ao público externo, tal como o mercado acionário, o poder público e os sindicatos, e é atendido pela contabilidade financeira por balanços patrimoniais e sociais. O segundo diz respeito ao público interno e à estratégia empresarial e é atendido por sistemas gerenciais estruturados de medição de desempenho (Sellitto, 2005).

Para Miranda e Silva (2002), a principal função da medição de desempenho é verificar se e em que grau a missão empresarial está sendo cumprida. Segundo os autores, ao estruturar-se um sistema de medição de desempenho, três perguntas devem ser respondidas: i) porque medir, exigindo clareza acerca da missão; ii) o que medir, exigindo que os principais campos de força intervenientes na missão sejam entendidos; e iii) como medir, exigindo que se relacionem as grandezas que operam os campos de força, geralmente latentes, com indicadores que apreendam seu comportamento. Para Kasul e Motwani (1995), antes de se propor um sistema de medição de desempenho, deve-se conhecer os fatores críticos para o sucesso da operação. Para Melnick et al. (2004), é a medição de desempenho que liga estratégia e realidade: estratégia sem medição é inútil, medição sem estratégia não faz sentido. Para Hronec (1993), as medições de desempenho são os sinais vitais da organização, comunicando a estratégia para baixo e os resultados para cima. Para Moreira (1996), um sistema de medição de desempenho é um conjunto de medidas referentes à organização como um todo e às suas partes, alinhadas com a visão de futuro e descrevendo as estratégias para alcançá-la. Para Müller (2003), medições de desempenho permitem a melhoria e a comparação com as melhores práticas, o benchmarking. Para Bourne et al. (2000), a medição de desempenho tem duas funções: medir o sucesso de uma estratégia e verificar a validade dos pressupostos assumidos ao formulá-la. Para Gasparetto (2003), a medição de desempenho deve ser sistêmica, integrando indicadores segundo uma regra e alterando-a se a estratégia ou o cenário de competição modificar-se. Para Arantes (1998), o desempenho deve ser medido por resultados finais, que justifiquem a existência da organização, integrados a resultados intermediários, que expressem o modo pelo qual a organização acredita que os resultados finais serão alcançados.

Melnick et al. (2004) falam em medições individuais, grupos de medições individuais e medições agregadas, das quais se obtém um senso de desempenho global, segundo as premissas de agregação. Sellitto (2005) fala em sistema de medição de desempenho, no qual as medições são os elementos e as hierarquias e composições de afinidade entre medições são as relações que as resumem em medições mais gerais. Bourne et al. (2000) dividem a implantação da medição de desempenho em: i) especificação, um processo cognitivo em que as visões de estrategistas são transformadas em objetivos e grandezas que os mensurem; ii) implementação, baseada em tecnologia de informação; e iii) uso das medições, na qual se atualizam as medições, em um processo permanente de aprendizado e percepção de mudanças no ambiente ou na estratégia. Lohman et al. (2004) julgam essencial o questionamento permanente da validade dos indicadores e a sua eventual atualização, sempre que o cenário de atuação se alterar.

Sellitto e Ribeiro (2004) propuseram uma sistemática para estruturar sistemas de medição, baseada na teoria das medições e na filosofia da ciência. Os autores propõem que o estudo de entes ou grandezas intangíveis, tais como o desempenho empresarial, deve se valer de construções abstratas que facultem a investigação por componentes estruturais. A construção mais abstrata é o termo teórico, que compreende e se sustenta em construtos, que, por sua vez, se sustentam em conceitos. Construtos e conceitos também são abstratos, porém o conceito é mais próximo da realidade e já pode se valer de variáveis manifestas, os indicadores, enquanto que os construtos ainda são representados por variáveis latentes. Construtos e conceitos estruturam a grandeza intangível em níveis hierárquicos, construídos por uma teoria ou por conhecimento empírico ou opinião de especialistas sobre a situação a medir.

\subsection{Medição de desempenho ambiental}

Segundo Cesàro (1992), há dois tipos de regulamentação sobre avaliação ambiental: como a francesa, que avalia todas as operações, menos as listadas; e como a italiana e a brasileira, que listam as operações de avaliação obrigatória. Segundo Pegado et al. (2001), a avaliação do desempenho ambiental já é feita, ao menos em parte, por instrumentos, tais como a avaliação de impacto ambiental e a análise de risco ambiental. Campos (2001) cita que metodologias de identificação de impactos ambientais, as Auditorias Ambientais e os Instrumentos de Avaliação de Impactos Ambientais, surgidas na década de 1980, evoluíram para Sistemas de Gestão Ambiental (SGA), 
modelos referenciais de gestão de impactos ambientais. Pearson e Barnes (1999) afirmam que a avaliação do desempenho ambiental não deve se limitar a relatórios e deve ser multidimensional, representada por múltiplos indicadores de desempenho. Acrescentam-se duas relevâncias: uma avaliação é baseada em julgamento de especialistas, que podem mudar conforme o especialista e o momento, o que não ocorre com medições baseadas em indicadores objetivos; e é difícil agregar resultados por relatórios, pois a avaliação final trará a subjetividade de quem agrega e de quem julga os relatos.

Rossetto (2003) cita uma proposta do Scientific Expert Group, grupo de trabalho da UNEP/UNESCO (United Nations Environment Programme - Programa Ambiental das Nações Unidas/United Nations Education, Science and Culture Organization - Organização das Nações Unidas para a Educação, a Ciência e a Cultura), para a avaliação integrada de bacias hidrográficas, mas que pode ser estendida a sistemas sócio-econômicos. O método produz uma estrutura balanceada ponderada em múltiplos níveis de indicadores. Bollmann (2001), ao comentar o método, salienta que a sua contribuição é não medir indicadores ambientais isolados ou separados por afinidade, mas criar um índice que os relacione e pondere, formulando um caminho para o desempenho ambiental ótimo global.

Informações de indicadores monitoram ciclos de melhoria contínua, comunicam seus resultados e podem subsidiar iniciativas de classificação e recuperação de áreas. Apesar disto, autores apontam que os indicadores ambientais mais utilizados em SGA são aqueles mais fáceis de medir ou já disponíveis na empresa, medidos por outros meios. Há menor preocupação de gestores em identificar quais são os indicadores que deveriam integrar uma medição ideal de desempenho ambiental (Thoresen, 1999; Olsthoorn et al., 2001; Ammenberg e Hjelm, 2002). Esta característica, citada por autores especialistas em desempenho ambiental, também é observada na medição de outras estratégias funcionais, tal como a de manufatura. Gestores podem preferir usar indicadores existentes, em vez de especificar aqueles que representem com mais acurácia o objetivo estratégico e o meio para alcançá-lo.

Dado que a medição do desempenho empresarial assume a forma de sistema, a medição de uma estratégia funcional, tal como a estratégia ambiental, inserida na estratégia empresarial, toma a forma de subsistema, como uma "caixa dentro de outra caixa". Considerações equivalentes às que se fazem em medição de desempenho empresarial podem ser feitas em medição de desempenho ambiental, na devida escala.

Zobel et al. (2002) definem desempenho ambiental como a informação analítica oferecida por um conjunto de indicadores que permite comparar vários setores em uma mesma empresa, ou várias empresas de uma indús- tria, com respeito a certos requisitos ambientais. Melo e Pegado (2006) definem desempenho ambiental como a influência que uma operação industrial causa no ambiente, diferente de desempenho gerencial, que é a eficiência na condução de práticas preservacionistas ou mitigatórias. Segundo os autores, a medição do desempenho ambiental tem sido menos enfatizada do que a medição da eficiência gerencial. Embora haja literatura para tal, o desempenho ambiental não surge de modo proporcional nas normas e nas práticas das empresas.

Melo e Pegado (2006) citam duas abordagens complementares para medição de desempenho ambiental: por indicadores de impacto ambiental e por indicadores de pressão ambiental. Impacto ambiental é o efeito ou mudança causada no estado do ambiente por uma atividade antrópica. Pressão ambiental é a medida da intensidade ou do potencial da atividade para causar o impacto. São pressões ambientais os fatores de produção que exigem consumo de recursos naturais ou com potencial de degradação ambiental, tais como consumo de materiais e água, ocupação de área, potencial de aquecimento global, emissões poluentes (Pegado et al., 2001). Por exemplo, operações de usinagem usam óleo solúvel, e este uso exerce uma pressão ambiental, maior ou menor, segundo a quantidade e o tipo de óleo. O impacto ambiental associado é a contaminação de solo ou águas por óleo. Impactos ambientais são apreendidos por grandezas que já se materializaram no ambiente, tais como a presença de óleo na água ou no solo. Pressões ambientais são apreendidas por grandezas-meio, com potencial para causar o impacto, tal como o requisito de óleo da usinagem, mas que não são a única causa do impacto, pois este pode ser oriundo de outras fontes.

Medir o impacto ambiental é um meio mais completo de medir o desempenho ambiental, mas exige mais informação e pode variar segundo as condições basais do ambiente e segundo efeitos complexos e multiimbricados que várias fontes simultâneas de contaminação podem produzir. Por ser mais simples, requerer menos informações e se valer de sistemas de informação já disponíveis, gestores podem escolher medir o desempenho ambiental apenas medindo as pressões ambientais, não os impactos (Melo e Pegado, 2006).

Ao concluir a revisão, deseja-se citar três modelos de sistemas de indicadores que guardam alguma relação com o que é proposto neste artigo: o Ecoblock, o modelo do World Resources Institute, o WRI e a metodologia da UNEP/UNESCO para avaliação de bacias hidrográficas.

O Ecoblock mede o desempenho ambiental de produtos, de projetos e operações e divide o termo teórico Desempenho Ambiental em sete construtos: uso de água; uso de recursos; uso do solo; emissão de gases geradores de efeito estufa; emissão de poluentes hídricos; 
emissão de poluentes atmosféricos; e geração de resíduos. Os construtos são calculados segundo indicadores e ponderações de importância técnicas ou regulamentares. Ao fim, os construtos são agregados em um índice global, que os proponentes do método chamam de Pegada Ecológica (Ecoblock, 2006). Embora a página do método cite sete construtos, Melo e Pegado (2006) relatam casos de aplicação em que cinco construtos foram calculados (consumo de água, consumo de material, uso do solo, emissões poluidoras e efeito estufa).

O modelo do WRI é mais generalista e se aplica mais a grandes espaços, tais como territórios ou setores econômicos e explora quatro construtos: poluição do ambiente; redução de recursos ambientais; risco ao eco-sistema; e impacto do ambiente no bem-estar humano. Segundo o relatório do WRI, pode-se chegar a um sistema de indicadores respondendo a três questões para cada construto: o que está acontecendo com o ambiente; porque está acontecendo; e o que estamos fazendo a respeito (Hammond et al., 1995).

Quanto ao modelo UNEP/UNESCO, este pode ser sintetizado em: i) definição do sistema a medir e seleção de indicadores básicos sócio-econômicos e ecológicos que o caracterizem; ii) agregação dos indicadores básicos em índices de segundo nível, tais como atividade econômica, saúde pública ou qualidade da água, vida selvagem, etc.; e iii) agregação dos índices de segundo nível em dois índices de terceiro nível, descritores dos subsistemas ecológico e econômico-social. Alguns dos objetivos do modelo são: i) calcular um valor numérico agregado que caracterizará o estado atual do sistema, sob as perspectivas ecológicas e sócio-econômicas; ii) permitir comparações objetivas entre sistemas distintos e ser base para escolha entre estratégias que modifiquem o estado destes sistemas, mas que compitam por recursos escassos; e iii) refletir mudanças de importância ou preferências de gestores no tempo e no espaço (Rossetto, 2003). Tais objetivos se coadunam com a definição de sistema de medição flexível de desempenho, apresentada em Sellitto (2005).

\section{Uso de métodos multicriteriais em decisão ambiental: o AHP}

A teoria das decisões é um campo de conhecimento que pode ajudar na tomada de decisão em situações complexas ou de incerteza. Um problema de decisão geralmente atrai a atenção de grupos com interesses divergentes, encerra visões controversas e conflituosas e tem múltiplos objetivos e alternativas. Um decisor ou grupo de decisores poderá ter que fazer trocas, os trade-offs, adotando uma alternativa que abra mão de um objetivo menos valioso, em prol de outro mais valioso, segundo multicritérios de avaliação de alternativas. A totalidade das conseqüências de decisões alternativas pode não ser conhecida a priori, nem mesmo uma distribuição de probabilidades destas consequiências. Adicionalmente, algumas alternativas de decisões assumidas podem levar a conseqüências irreversíveis, o que aumenta a responsabilidade de quem decide (Keeney e Raiffa, 1976). Decisões acerca de problemas ambientais têm estas características, pois carregam um grau de incerteza sobre as consequiências que as alternativas ou estratégias disponíveis acarretarão, em relação aos múltiplos objetivos do problema. Deste modo, é considerável o campo de aplicação da teoria da decisão e de métodos multicriteriais em gerenciamento ambiental (Tzionas et al., 2004). Estes autores listam pesquisadores que trataram a incerteza inerente aos problemas ambientais com métodos inexatos de apoio à decisão.

Em decisão sob múltiplos critérios, o grupo de trabalho pode incluir partes interessadas, de dentro e de fora da empresa, especialistas no assunto e um analista de decisão. Com base nos vários pontos de vista em jogo, o problema é dividido nos múltiplos aspectos de interesse, que serão os critérios de julgamento, são calculadas suas importâncias relativas e listadas as alternativas de decisão. A forma canônica do problema é: um enunciado e um conjunto de alternativas $\mathbf{A}$, que deverão ser julgadas segundo um conjunto de critérios $\mathbf{C}$, cada critério $C_{\mathrm{i}}$ influenciando o enunciado do problema com um peso $w_{\mathrm{i}}$. Dado que já se tenham $\mathbf{A}$ e $\mathbf{C}$, é necessário um método para encontrar os $w_{\mathrm{i}}$ (Keeney e Raiffa, 1976; Chiou e Tzeng, 2002).

Dentre os métodos existentes, o processo de análise hierárquica AHP (Analytic Hierarchy Process) é, segundo Salomon e Montevechi apud Salomon (2002), possivelmente o mais conhecido e mais usado em decisão multicriterial. O método é abundantemente explorado na literatura (Partovi et al., 2002; Liu e Hai, 2005) e sua fundamentação e procedimentos são descritos em Saaty (1991) e Forman e Selly (2001).

Segundo Forman e Selly (2001), o AHP obriga decisores a considerar percepções, experiências, intuições e incertezas de modo racional, gerando escalas de prioridade ou pesos. É uma metodologia de decisão compensatória, porque alternativas frágeis para um objetivo, podem ter desempenho forte em outros objetivos. O AHP opera em três passos: i) descrição da situação complexa de interesse sob a forma de hierarquias conceituais, formadas por critérios e subcritérios até que, segundo os decisores, o enunciado do problema tenha sido suficientemente descrito; ii) comparação duas a duas das influências dos critérios e sub-critérios nos entes superiores da hierarquia; e iii) computação dos resultados. O enunciado do problema deve ficar estruturado de modo hierárquico (Figura 1).

A importância relativa dos critérios surge por comparações pareadas. Para um nível com $n$ critérios, são requeri- 
das $n .(n-1) / 2$ comparações entre $a_{\mathrm{i}}$ e $a_{\mathrm{j}}, \forall i, j$, construindose uma matriz de preferências $C_{\mathrm{i}, \mathrm{j}}(n \times n)$ (Saaty, 1991). A comparação é feita respondendo-se às questões:

- ao influenciar o nível acima, o critério $a_{i}$ é mais importante, menos importante ou igual em importância ao critério $a_{j}, \forall i, j$; e

- para os $a_{i, j}$ não equivalentes, e dado que $a_{i}$ é mais importante do que $a_{j}$, $a_{i}$ é: (i) um pouco mais importante do que $a_{j}$; (ii) muito mais importante do que $a_{j}$; (iii) muito fortemente mais importante do que $a_{j}$; ou (iv) absolutamente mais importante do que $a_{j}$.

A matriz de preferências é preenchida segundo a Tabela 1. Valores intermediários se destinam a situações intermediárias, nas quais foi necessário discernir mais claramente entre duas alternativas muito parecidas, segundo o critério de julgamento.

Por fim, calcula-se a importância relativa dos critérios, encontrando-se os autovetores com máximos autovalores da matriz. Os componentes do autovetor são as prioridades dos critérios e o autovalor dá a medida de consistência do julgamento, dentro das bases propostas pelo método. Se $\mathbf{A}$ for a matriz de comparações, deve-se encontrar

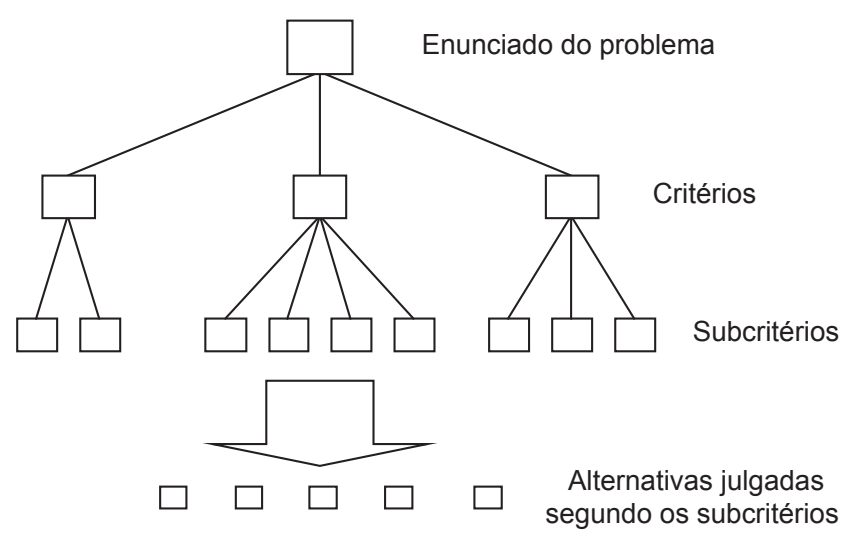

Figura 1. Estrutura de decisão hierárquica (fonte: Adaptado de Forman e Selly, 2001).

Tabela 1. Opções de preferência com base em comparação pareada (fonte: Saaty, 1991, p. 22 e 23).

\begin{tabular}{|c|c|c|c|}
\hline $\begin{array}{c}\text { se } a_{i} \text { em relação a } \\
a_{j}=\end{array}$ & $\begin{array}{c}\text { então } \\
c_{i j}=\end{array}$ & $\begin{array}{c}\text { se } a_{i} \text { em relação } \\
\text { a } a_{j}=\end{array}$ & $\begin{array}{c}\text { então } \\
c_{i j}=\end{array}$ \\
\hline igual & 1 & igual & 1 \\
\hline $\begin{array}{l}\text { um pouco mais } \\
\text { importante }\end{array}$ & 3 & $\begin{array}{l}\text { um pouco menos } \\
\text { importante }\end{array}$ & $1 / 3$ \\
\hline muito mais importante & 5 & $\begin{array}{l}\text { muito menos impor- } \\
\text { tante }\end{array}$ & $1 / 5$ \\
\hline $\begin{array}{l}\text { fortemente mais } \\
\text { importante }\end{array}$ & 7 & $\begin{array}{l}\text { fortemente mais } \\
\text { importante }\end{array}$ & $1 / 7$ \\
\hline $\begin{array}{l}\text { absolutamente mais } \\
\text { importante }\end{array}$ & 9 & $\begin{array}{l}\text { absolutamente mais } \\
\text { importante }\end{array}$ & $1 / 9$ \\
\hline
\end{tabular}

o vetor de prioridades $\mathbf{w}$, tal que satisfaça a Equação 1. A razão de consistência $C R$ é calculada pela Equação 2.

$$
\begin{array}{ll}
\mathbf{A} \cdot \mathbf{w}=\lambda_{\text {max }} \cdot \mathbf{w} & (\text { Equação 1); } \\
C R=\left[\lambda_{\max }-n\right] /[I R .(n-1)] & (\text { Equação 2); }
\end{array}
$$

na qual: i) $n$ é o número de critérios; ii) $\lambda_{\max } \leq n$ é o maior autovalor; e iii) $I R$ é o índice randômico médio, extraído de tabela obtida por simulações com amostras de matrizes $n$-dimensionais. A tabela surge em Saaty, 1991, p. 27. Por exemplo, se um decisor considera $a_{1}$ uma vez e meia mais importante que $a_{2}$ e $a_{2}$ duas vezes mais importante que $a_{3}$, este decisor deve considerar $a_{1}$ três vezes mais importante que $a_{3}$. Se for outro o julgamento, há inconsistência, medida pela $C R$. A $C R$ é a probabilidade de que os valores da matriz sejam puramente aleatórios e, portanto, não constituam uma estrutura de preferências originada de um julgamento racional. Saaty (1991) sugere arbitrariamente que se aceite $C R<0,10$, do contrário recomenda a identificação e reformulação dos julgamentos que contribuíram para a inconsistência. Hogart (1988), no entanto, alerta que se deve contar com certa inconsistência no modelo mental e em julgamentos de decisores, o que pode ser apreendido pela $C R$.

\section{A pesquisa: o MDA}

Wilson e Sasseville (1999, apud Pegado, Melo e Ramos, 2001) apontam duas abordagens distintas para medição de desempenho ambiental: i) medidas exclusivas para uma operação segundo uma recomendação, tal como a ISO 14031; e ii) medidas generalistas e comparáveis para uso em qualquer operação. Deseja-se propor uma terceira abordagem, com elementos de ambas, uma medição flexível de desempenho. A medição vale para uma operação e produz um número final agregado, mas o método é replicado em outras operações, chegando a outro número final agregado. Apesar das medições e ponderações serem específicas para cada operação, como as considerações feitas nos desenvolvimentos são homólogas, os valores finais são comparáveis. Em resumo, é o método que é sistêmico, não apenas os resultados.

O MDA (medição de desempenho ambiental) desdobra o termo teórico Desempenho Ambiental em construtos, os fatores que influenciam o termo teórico, e em indicadores ambientais e de gestão, que explicam e sustentam os construtos. A seguir, calcula, segundo os decisores, as importâncias relativas de construtos e indicadores, gerando uma combinação linear para o desempenho ambiental da operação. As alternativas de decisão são operações a medir ou estratégias a julgar. Caso os planos das estratégias compitam por recursos limitados, a combinação linear torna-se a função-objetivo de um problema de otimização. Em ambos os casos, chega-se 
à forma canônica de problema de decisão multicriterial: um enunciado intangível e complexo, com incertezas e controvérsias, o desempenho ambiental; os critérios e subcritérios, os construtos e indicadores; e as alternativas, operações a medir ou estratégias a julgar. A solução segue o formato de decisão multicriterial: i) grupo focado com especialistas define a estrutura de medição e a pondera; e ii) aplicação da estrutura à(s) operação(ões), cálculo do(s) índice(s) agregado(s), comparação e ordenação dos resultados.

\subsection{Aplicação e resultados}

Para exemplificar e robustecer o método, ele foi aplicado a uma operação de manufatura de autopeças, com reconhecida atuação em gestão ambiental. A técnica de pesquisa é o estudo de caso exploratório. Segundo Eckstein et al. (1975, apud Roesch, 1999), um estudo de caso pode contribuir para uma teoria de cinco modos: i) oferecer para posteriores estudos uma descrição profunda e específica de um caso; ii) interpretar eventuais regularidades como evidências de postulados teóricos mais gerais; iii) construir uma situação deliberada para testar uma idéia, de cujo resultado se pode propor uma teoria; iv) fazer sondagens plausíveis acerca de uma teoria; e v) o caso crucial, que apoia ou refuta a teoria. Entende-se que a contribuição é do terceiro tipo: uma situação construída para o teste de uma idéia.

O grupo focado foi formado por uma doutora e dois mestrandos especialistas em gestão ambiental, dois especialistas gestores do sistema ambiental da empresa que sedia a operação estudada, com graduação em engenharia, e foi moderado por um doutor em engenharia, especialista em apoio à decisão, que atuou como analista de decisão. Os procedimentos do grupo focado seguiram o proposto em Ribeiro e Newmann (2003).

O moderador propôs cinco questões como tema de discussão. A partir das respostas e das discussões que se seguiram, o moderador elaborou o que era o objetivo do grupo, a estrutura de medição de desempenho ambiental da operação de manufatura estudada. As questões foram: i) questão inicial: o que o grupo entende por desempenho ambiental; ii) questão de transição: se o grupo reconhece que a operação tem requisitos de desempenho ambiental a cumprir; iii) questões centrais: como o grupo descreve e interpreta estes requisitos ambientais; iv) questão de resumo: quais os fatores ligados à operação de manufatura que o grupo reconhece como capazes de afetar o desempenho ambiental; e v) questão final: como cada um dos fatores acima é constituído e que variáveis manifestas podem explicá-los.

O moderador extraiu das discussões, e os participantes aceitaram, cinco construtos de desempenho ambiental: i) geração de resíduos sólidos; ii) emissão de efluentes industriais; iii) consumo de recursos naturais; iv) práticas de gestão ambiental; e v) emissões atmosféricas. Ao fim da sessão, o grupo aplicou, sob moderação, o $A H P$ para a ponderação dos construtos, chegando a uma $C R=0,03$. Resultou a Equação 3 e a estrutura da Figura 2.

MDA $=0,1102 . \Sigma$ [resíduos] $+0,2689 . \Sigma$ [efluentes] + $0,1692 . \Sigma$ [recursos] $+0,029 . \Sigma$ [gestão] $+0,422 . \Sigma$ [emissões]

(Equação 3)

A estrutura de preferência de grupo, gerada pelo $A H P$, surge na Tabela 2. As linhas são apresentadas em ordem decrescente de importância. Os valores acima da diagonal são monotonamente crescentes, ou seja, ou crescem

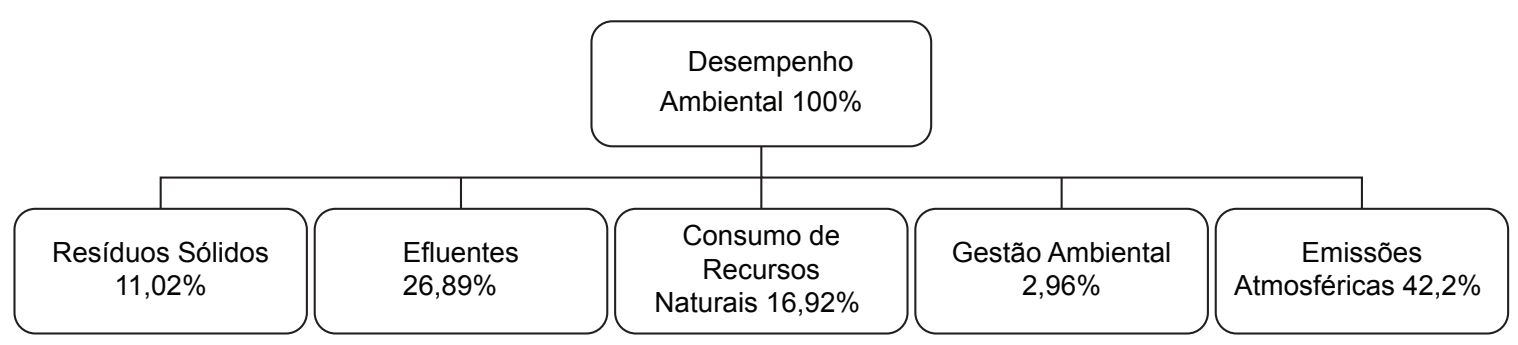

Figura 2. Decisão hierárquica para a operação estudada.

Tabela 2. Estrutura de preferências dos decisores.

\begin{tabular}{lcccccc}
\hline & Emissões & Efluentes & Recursos & Resíduos & Gestão & IR (\%) \\
\hline Emissões & $\mathbf{1}$ & 2 & 3 & 4 & 9 & 42,20 \\
Efluentes & $1 / 2$ & $\mathbf{1}$ & 2 & 3 & 8 & 26,89 \\
Recursos & $1 / 3$ & $1 / 2$ & $\mathbf{1}$ & 2 & 7 & 16,92 \\
Resíduos & $1 / 4$ & $1 / 3$ & $1 / 2$ & $\mathbf{1}$ & 6 & 11,02 \\
Gestão & $1 / 9$ & $1 / 8$ & $1 / 7$ & $1 / 6$ & $\mathbf{1}$ & 2,96 \\
\hline \multicolumn{1}{r}{} \\
\hline
\end{tabular}


ou ficam iguais, da esquerda para a direita, evidenciando a coerência dos julgamentos, já apontada pela $C R$ de $3 \%$. Valores de $C R$ abaixo de $10 \%$ são satisfatórios, segundo os proponentes do método.

A baixa importância da gestão ambiental chamou a atenção do analista de decisão. Os membros do grupo justificaram esta baixa preferência, manifestando preocupação em não controlar apenas a eficiência das práticas gerenciais, as atividades-meio, preocupando-se mais em controlar o impacto da operação no ambiente, as atividades-fim da gestão ambiental.

Na segunda sessão, o grupo definiu os indicadores de sustentação dos construtos. $\mathrm{O}$ grupo entendeu que não havia informação suficiente para julgar importâncias dentro dos construtos e usou o critério de Laplace: importâncias iguais. Também definiu as faixas para as classes de desempenho, de péssimo a ótimo. O sistema de indicadores e as faixas de desempenho adotadas surgem na Tabela 3.

O grupo usou dados de desempenho dos últimos doze meses, a legislação vigente (para efluentes e emissões atmosféricas), os objetivos e metas ambientais aprovados pela alta administração (requisito 4.3.1 da
ISO 14001: 2004), requisitos da política ambiental, planejamento estratégico da organização e limites de referências internacionais, tais como o EPA - Environmental Protection Agency. Algumas faixas de desempenho referem-se a requisitos legais críticos, constantes da licença de operação emitida pelo órgão ambiental. Não foram necessárias novas medições, mas isto não foi proposital, pois não foi imposto como restrição ao grupo focado o uso de medidas existentes. A operação dispõe de outras informações em base de dados, que o grupo não julgou necessárias neste momento.

Os indicadores são quantitativos ou categóricos. Os quantitativos são de mensuração direta na natureza e possuem procedimentos padronizados de medição, constante no manual do SGA. Os categóricos se aplicaram quando não foi possível discernir na natureza, devido aos múltiplos aspectos e à subjetividade da medição, uma variável proxi unificada satisfatória. Nestes casos, usaram-se questionários com gestores da empresa, com a seguinte escala para o desempenho do indicador: $[1=$ péssimo; 2 = ruim $; 3=$ médio $; 4=$ bom $; 5=$ ótimo $]$. As categorias são distribuídas proporcionalmente dentro dos campos numéricos.

Tabela 3. Indicadores e faixas de desempenho ambiental.

\begin{tabular}{|c|c|c|c|}
\hline Construtos & Indicadores & Tipo & [péssimo-ótimo] \\
\hline \multirow[t]{3}{*}{$\begin{array}{l}\text { Resíduos } \\
\text { Sólidos }\end{array}$} & $\begin{array}{l}\text { Percentual de resíduos reciclados = resíduos reciclados/total de resíduos } \\
\text { sólidos gerados }\end{array}$ & Quantitativo & $0-100 \%$ \\
\hline & $\begin{array}{l}\text { Percentual de resíduos perigosos = resíduos perigosos/total de resíduos } \\
\text { sólidos gerados }\end{array}$ & Quantitativo & $10-0 \%$ \\
\hline & $\begin{array}{l}\text { Quantidade de resíduos enviados a aterros }=\mathrm{kg} \text { de resíduos/funcionário a } \\
\text { cada mês }\end{array}$ & Quantitativo & $10-3[\mathrm{~kg} / \mathrm{f}] / \mathrm{mês}$ \\
\hline \multirow[t]{5}{*}{ Efluentes } & Concentração de Cromo & Quantitativo & $1,0-0,05 \mathrm{mg} / \mathrm{L}$ \\
\hline & Concentração de Cobre & Quantitativo & $2,0-0,01 \mathrm{mg} / \mathrm{L}$ \\
\hline & Concentração de Chumbo & Quantitativo & $1,0-0,01 \mathrm{mg} / \mathrm{L}$ \\
\hline & Óleos e graxas & Quantitativo & $70-10 \mathrm{mg} / \mathrm{L}$ \\
\hline & Vazão: Volume de efluentes tratados/hora ativa & Quantitativo & $0-10 \mathrm{~m}^{3} / \mathrm{h}$ \\
\hline \multirow{4}{*}{$\begin{array}{l}\text { Consumo de } \\
\text { recursos } \\
\text { naturais }\end{array}$} & Consumo de água: volume de água/hora ativa & Quantitativo & $0,16-0,08 \mathrm{~m}^{3} / \mathrm{h}$ \\
\hline & Consumo de energia elétrica: Consumo de energia/hora ativa & Quantitativo & $47-43 \mathrm{kWh} / \mathrm{h}$ \\
\hline & Consumo de aço: Como são as ações que otimizam este consumo? & Categórico & $1-5$ \\
\hline & $\begin{array}{l}\text { Consumo de óleos lubrificantes: Como são as ações que otimizam este } \\
\text { consumo? }\end{array}$ & Categórico & $1-5$ \\
\hline \multirow[t]{4}{*}{$\begin{array}{l}\text { Gestão } \\
\text { ambiental }\end{array}$} & $\begin{array}{l}\text { Atendimento legal: requisitos legais do SGA julgados atendidos/total de } \\
\text { requisitos legais }\end{array}$ & Quantitativo & $0-100 \%$ \\
\hline & $\begin{array}{l}\text { Investimentos ambientais: } \$ \text { usado no SGA/ } \$ \text { faturamento gerado pela } \\
\text { operação }\end{array}$ & Quantitativo & $0-0,2 \%$ \\
\hline & $\begin{array}{l}\text { Fornecedores ambientais qualificados: Quantidades de fornecedores } \\
\text { qualificados pelo SGA/total de fornecedores ambientais }\end{array}$ & Quantitativo & $0-100 \%$ \\
\hline & $\begin{array}{l}\text { Ações corretivas: ações concluídas satisfatoriamente/total de ações } \\
\text { recomendadas pelo SGA }\end{array}$ & Quantitativo & $0-100 \%$ \\
\hline \multirow{3}{*}{$\begin{array}{l}\text { Emissões } \\
\text { atmosféricas }\end{array}$} & Compostos orgânicos voláteis & Quantitativo & $20-0 \mathrm{mg} / \mathrm{Nm}^{3}$ \\
\hline & Particulados & Quantitativo & $150-10 \mathrm{mg} / \mathrm{Nm}^{3}$ \\
\hline & Emissão de gases causadores de efeito estufa & Quantitativo & $100-20 \%$ \\
\hline
\end{tabular}


O primeiro construto mede a situação dos resíduos sólidos, que é investigada pelos percentuais de resíduos sólidos que são destinados a algum tipo de reciclagem; do percentual de resíduos perigosos gerados; e pela quantidade de resíduos orgânicos não-secos, ou seja, que serão destinados a aterros sanitários, gerados por funcionário a cada mês.

O segundo construto mede a situação dos efluentes, que é investigada pelas concentrações de cromo, cobre e chumbo e situação de óleos e graxas, medidas em mg/L, e a vazão de efluentes tratados, medidos em volume de efluentes tratados por hora ativa da operação. Para os valores ótimos, consideraram-se limites para águas doces de classe II, segundo o Conama 357/2005, e aí se enquadra o trecho do rio Gravatai no qual a operação lança os efluentes, o que é mais restritivo do que o estipulado na legislação, por considerar-se que o rio já apresenta algum grau destes elementos. Como valores péssimos, foram tomados os dobros dos permitidos pelo Conama 357/2005 para o caso.

O terceiro construto mede o consumo de recursos naturais e é capturado pela situação de consumo de água, energia elétrica, aço e óleos lubrificantes. Os dois primeiros indicadores são mensuráveis, respectivamente, pelo volume de água captada e pelo número de quilowatts-hora requeridos por hora de operação ativa, a potência elétrica média da operação. Já, quanto aos dois últimos, o grupo não conseguiu capturar todos os aspectos envolvidos no indicador por meio de uma única variável, lançando mão de variáveis categóricas. O consumo de aço é afetado por: melhorias no desenvolvimento de chapas, que permitem reduzir o número de chapas retangulares requeridas por produto; esforços de substituição de aço por outros materiais e; aumento de capabilidade, o que reduz refugos e retrabalhos. O consumo de óleos lubrificantes é afetado por: melhorias em manutenção, principalmente por procedimentos de MPT, Manutenção Produtiva Total, que reduz perdas por vazamentos; modificações em equipamentos, que passaram a usar lubrificação centralizada ou outros tipos de óleos, menos agressivos e de mais vida útil; e administração do ciclo de vida de lubrificantes.

O quarto construto faz a autocrítica do SGA da empresa que sedia a operação medida e considera o desempenho em gestão ambiental, por meio de quatro indicadores: o percentual de requisitos legais atendidos; o percentual de faturamento gerado pela operação reaplicado em investimentos ambientais; o percentual de fornecedores de insumos e serviços ambientais já certificados por procedimentos do SGA; e o percentual de ações recomendadas pelo SGA já concluídas satisfatoriamente. Observa-se que há riscos em se tomar qualquer um dos quatro indicadores isoladamente. Um gestor interessado em aumen- tar apenas o primeiro indicador iniciaria suas ações pelos requisitos legais mais simples, independente de importância; para aumentar o segundo indicador, faria primeiro os investimentos mais vultosos, independente de retorno; para o terceiro, certificaria primeiro os fornecedores mais próximos ou mais fáceis, independente do volume de fornecimentos; e, quanto ao quarto indicador, priorizaria ações fáceis e baratas, independente de retorno e investimento. Considera-se relevante observar os quatro indicadores em conjunto e evitar otimizações parciais.

O quinto construto mede as emissões atmosféricas, por intermédio de três indicadores: compostos orgânicos voláteis; particulados; e gases causadores de efeito estufa. Esta última medição é feita por um cartão visual, com a escala Ringelmann, especificada pelo Código Nacional de Trânsito, em que a densidade medida em padrão visual de cores varia de $0 \%$ a $100 \%$.

Especificados os indicadores, a empresa aportou ao grupo as informações para o cálculo do índice. Esta foi a primeira vez que o grupo travou contato com a base de dados da operação, o que garante que a escolha de indicadores não foi influenciada por indicadores existentes. O desempenho ambiental alcançou $84,37 \%$ do máximo possível e é sumarizado na Tabela 4.

Na primeira coluna, surge a importância relativa do construto; na segunda coluna as importâncias relativas internas ao construto; na terceira coluna o desempenho relativo do indicador e, na última coluna, chega-se à contribuição absoluta do indicador ao desempenho ambiental da operação. A contribuição de cada indicador é obtida pela multiplicação entre as importâncias relativas do construto, do indicador e o desempenho relativo. O construto 1, por exemplo, é descrito por três indicadores com importâncias relativas de $33,33 \%$ dos $11,02 \%$ do construto. A contribuição é de 10,54 pontos percentuais dos 11,02 possíveis. O desempenho relativo do construto 1 é de $95,7 \%$. Os desempenhos relativos dos outros construtos são, respectivamente: $100 \%$; 55,5\%; 80,3\%; e 83,3\%.

\section{Discussão}

Durante as sessões, houve dúvidas sobre indicadores com limites legais e de medição contínua. Como são valores probabilísticos, as medições são amostras de uma população infinita. Portanto, decidiu-se não apenas considerar a média da amostra, mas também testar a aderência dos dados à distribuição normal. Os membros da amostra que se mostraram como outliers (fora da distribuição, para mais ou para menos) foram excluídos do cálculo. No caso de efluentes, a medição considera o valor basal das concentrações do rio e não apenas a contribuição do efluente, ou seja, a operação compensa outras fontes. Observou-se uma deficiência na medição da concentração do cromo. Seria necessário incluir o limite de cromo 
hexavalente, ou como uma medição a ser composta com o cromo total no indicador, ou até mesmo como indicador autônomo. A discussão sobre este ponto é remetida à continuidade, mas aponta-se a priori uma sugestão de faixas de desempenho [péssimo $=0,2 ;$ ótimo $=0$ ].

Outro aspecto que interessa discutir é o uso do MDA como elo realimentador da estratégia ambiental da empresa. Para tanto, na Tabela 5, apresentam-se os desempenhos dos construtos, em pontos percentuais, as importâncias relativas, que são as máximas contribuições dos construtos, as lacunas de desempenho e os desempenhos relativos, já mencionados.

Os construtos com maior lacuna de desempenho, o uso de recursos naturais e as emissões atmosféricas, devem ser priorizados em ações de controle estratégico. Os resultados apontam que a empresa tem priorizado ações de controle em resíduos sólidos e efluentes. A maior lacuna de desempenho é relativa ao consumo de recursos naturais, o que indica que a empresa deve focalizar suas ações para tecnologias limpas, visando à otimização de processos e redução do desperdício. Para maximizar o desempenho ambiental, recomendam-se reduções dos consumos de água, energia, aço e óleos lubrificantes e de emissões atmosféricas de compostos orgânicos voláteis e fumaça preta. A empresa informou que, recentemente, ativou um programa de reaproveitamento de água industrial, o que reduzirá a captação, e poderá estudar otimizações de processos para reduzir

Tabela 4. Cálculo do índice de desempenho ambiental.

\begin{tabular}{llcc}
\hline $\begin{array}{c}\text { Construtos e importância } \\
\text { relativa }\end{array}$ & \multicolumn{1}{c}{$\begin{array}{c}\text { Indicadores e importância relativa do } \\
\text { indicador dentro do construto }\end{array}$} & $\begin{array}{c}\text { Desempenho } \\
\text { relativo \% do } \\
\text { indicador }\end{array}$ & $\begin{array}{c}\text { Contribuição em } \\
\text { pontos percentuais } \\
\text { (pp) do indicador }\end{array}$ \\
\hline Resíduos & \% de Reciclagem - 33,3\% & 87,0 & 3,19 \\
$11,02 \%$ & Geração de Contaminados - 33,3\% & 100 & 3,67 \\
& Geração de Resíduos Orgânicos (não-secos) - 33,3\% & 100 & 3,67 \\
\hline Efluentes & Vazão - 20\% & 100 & 5,38 \\
$26,89 \%$ & Cromo - 20\% & 100 & 5,38 \\
& Chumbo - 20\% & 100 & 5,38 \\
& Cobre - 20\% & 100 & 5,38 \\
& Óleos e Graxas - 20\% & 100 & 5,38 \\
\hline Consumo de Recursos Naturais & Consumo de Água - 25\% & 100 & 4,23 \\
$16,92 \%$ & Consumo de Energia Elétrica - 25\% & 46,9 & 1,98 \\
& Consumo de Aço - 25\% & 25,0 & 1,06 \\
& Consumo de Óleos Lubrificantes - 25\% & 50,0 & 2,12 \\
\hline Gestão & Atendimento Legal - 25\% & 98,0 & 0,73 \\
$2,96 \%$ & Investimentos Ambientais - 25\% & 90,0 & 0,67 \\
& Fornecedores Ambientais Qualificados - 25\% & 100 & 0,74 \\
& Situações de Ações Corretivas e Preventivas - 25\% & 33,0 & 0,24 \\
\hline Emissões Atmosféricas & Emissão de Compostos Orgânicos Voláteis - 33,3\% & 75,0 & 10,55 \\
$42,20 \%$ & Emissão de Particulados - 33,3\% & 100 & 14,07 \\
& Emissão de Fumaça Preta (CO2,...) - 33,3\% & 75,0 & 10,55 \\
& & Total & 84,37 \\
\hline
\end{tabular}

Tabela 5. Análise numérica de desempenho por construto.

\begin{tabular}{lcccc}
\hline & Desempenho & Importância relativa & Lacuna & Desempenho relativo \\
\hline Resíduos sólidos & 10,54 & 11,02 & 0,48 & $95,6 \%$ \\
Efluentes & 26,89 & 26,89 & 0,00 & $100,0 \%$ \\
Recursos naturais & 9,39 & 16,92 & 7,53 & $55,5 \%$ \\
Gestão ambiental & 2,38 & 2,96 & 0,58 & $80,3 \%$ \\
Emissões atmosféricas & 35,17 & 42,20 & 7,03 & $83,3 \%$ \\
Soma & 84,37 & 100 & 15,62 & $95,6 \%$ \\
\hline
\end{tabular}


os aspectos citados. A gestão ambiental, embora com contribuição máxima possível baixa, pode melhorar seu desempenho no controle de ações corretivas e preventivas, já que apresentou índice de apenas 33\%. A empresa já aprovou o controle de ações corretivas via sistema de informação on-line.

Outra análise que pode ser feita diz respeito à disputa interna por recursos restritos. Para tanto, pode-se examinar a Figura 3, que traz, no eixo $x$, a importância percentual do construto e, no eixo $y$, o desempenho relativo, informados na segunda e na quarta coluna da Tabela 5. A situação ideal é quando todos os construtos apresentam máximo desempenho, mas, se forem necessários trade-offs, ou seja, abrir mão de um recurso em troca de outro, o estrategista deve desativar recursos usados em construtos cujos desempenhos são maiores do que as importâncias e alocálos a recursos de mais importância do que desempenho, em escalas relativas. Para a operação estudada, recursos financeiros que estão sendo usados no sistema de gestão e nos resíduos sólidos podem ser transferidos à gestão dos recursos naturais, e recursos usados nos efluentes podem ser transferidos às emissões atmosféricas.

Finalmente, pode-se comparar o resultado a que o MDA chegou na operação estudada com o Ecoblock, já citado. Ressalva-se mais uma vez que o MDA é flexível e a comparação vale apenas para a operação estudada e para os construtos a que o MDA chegou. Os construtos do Ecoblock apresentados em Melo e Pegado (2006) são: consumo de água, consumo de material, uso do solo, emissões poluidoras e efeito estufa. Os construtos da aplicação do MDA são: resíduos sólidos; efluentes; recursos naturais; gestão ambiental; e emissões atmosféricas. Os construtos consumo de água e consumo de materiais do Ecoblock são similares a aspectos do construto recursos naturais do MDA; os construtos emissões poluidoras e efeito estufa do Ecoblock são similares a aspectos dos construtos resíduos sólidos, efluentes e emissões atmosféricas do MDA; os construtos uso do solo no Ecoblock e gestão ambiental do MDA não têm similaridade no outro método.

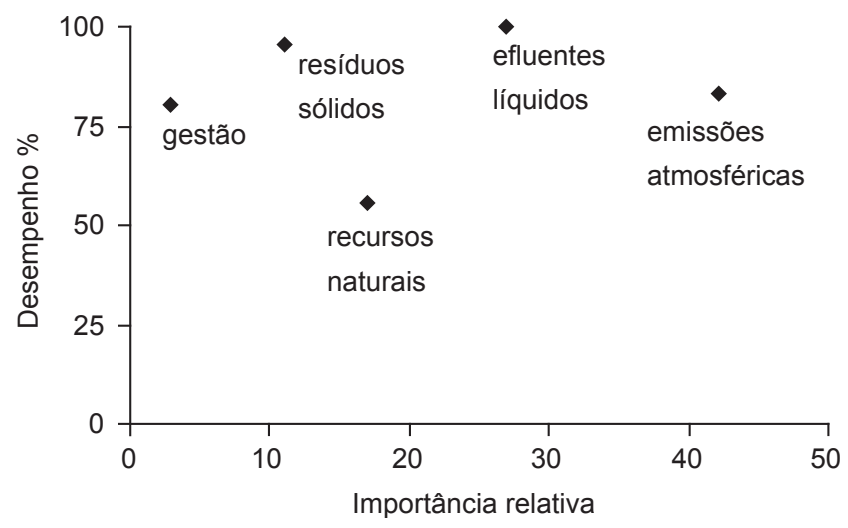

Figura 3. Análise da estratégia ambiental.

\section{Considerações finais e continuidade de pesquisa}

Apresentou-se, pelo estudo de caso, o MDA. O método relaciona, segundo um formato de hierarquia, as medições de desempenho de diversos indicadores ambientais, e calcula a importância dos construtos que agregam estes indicadores. Se comparada a outras metodologias de medição de desempenho ambiental, o MDA antes identifica e prioriza os fatores que afetam o desempenho ambiental, para depois definir os indicadores a serem medidos. Com isto, evita-se a utilização de indicadores desalinhados do processo de gestão ambiental e, principalmente, evita-se cair na armadilha de usar indicadores que a empresa já tem ou já gerencia e, portanto, provavelmente, já são de elevado desempenho.

O MDA não é rígido ( $h a r d$ ), mas flexível (soft) e não visa a aplicar a Equação 3 a uma operação, mas permitir que qualquer operação construa a sua própria equação. Como o resultado final é dado em percentual do máximo resultado possível, podem-se comparar desempenhos ambientais entre operações participantes de diferentes processos.

Uma crítica que pode ser feita ao método diz respeito à subjetividade do grupo focado. Para evitar que o grupo tenda a favorecer a gestão sob julgamento, este pode ser composto por especialistas ad hoc, sem interesse na operação, mas que, durante os trabalhos, venham a conhecê-la, para não deixar de apontar aqueles aspectos que a empresa pode e deve alavancar. Outra crítica diz respeito ao método $A H P$, que traz em seu bojo uma parcela de inconsistência e tem sofrido críticas acerca de sua resposta quando há entradas ou saídas de critérios. O uso do $A H P$ foi uma delimitação do projeto de pesquisa no qual o caso se insere. Caso esta crítica seja insuperável, a contribuição essencial do caso passa a ser o método e não o resultado específico do caso.

Conclui-se observando que o desempenho ambiental da empresa estudada é considerado como sendo um referencial em sua região. Portanto, a medição próxima a $85 \%$ de eficácia na política ambiental confirma esta visão. Outro fator de importância para a empresa é manter o método de avaliação do desempenho ambiental alinhado com sua evolução empresarial e tecnológica. O surgimento de novos requisitos legais ou normativos e a introdução de novos produtos e processos deve motivar análise crítica e eventual recalibração do MDA, na qual são revisados construtos e importâncias. A organização deve ficar atenta, pois novas leis e normas podem alterar ou acrescentar exigências ambientais, o que se reflete na medição pela criação ou retirada de indicadores e construtos ou alterações nas faixas de indicadores.

Quanto a eventuais recalibrações, alerta-se que, quando se atingem valores próximos a $100 \%$, diminui a moti- 
vação para novas melhorias, o que é um argumento para a recalibração de objetivos. No entanto, também se corre o risco de perder a história cada vez que se reinicia o processo de medição. Uma alternativa para esta dúvida é modificar a escala para comunicação geral de resultados dentro da organização, para mantê-la motivada a melhorar o desempenho ambiental, mas não deixar de medir segundo a escala antiga, ampliada para comportar uma nova graduação, por exemplo, Mais do que ótimo. Neste caso, é possível que o valor final ultrapasse os cem pontos percentuais, o que torna a escala histórica absoluta e não mais relativa. Este procedimento paralelo pode ser mantido até que não haja mais sentido em conservar a linha comparativa, o que pode se dar, por exemplo, com a mudança no processo produtivo ou no produto principal da operação de manufatura.

O estudo do caso abriu frentes de interesse para pesquisa. Como continuidade sugere-se: i) o acompanhamento do índice de desempenho ambiental na mesma operação e a verificação dos impactos de ações tomadas no resultado final; ii) a replicação do método nas demais operações que se situam na bacia do rio Gravataí, comparando os impactos causados pelas empresas; e iii) a definição de importâncias relativas para cada indicador e a elaboração de um manual de aplicação deles, que pode se tornar um modelo de referência de gestão exclusivo da manufatura, independente do SGA da empresa.

\section{Agradecimentos}

Deseja-se reconhecer o papel da empresa que sediou o estudo de caso e a importância dada pela UAPPG da UNISINOS aos esforços de pesquisa do PPGEPS-UNISINOS. Deseja-se também salientar a importância do portal de periódicos da CAPES, no qual se buscou uma importante parte das fontes de pesquisa. Por fim, agradece-se aos comentários dos referees anônimos e aos participantes do grupo focado de pesquisa.

\section{Referências Bibliográficas}

AMMENBERG, J.; HJELM, O.; QUOTES, P. The Connection Between Environmental Management Systems and Continual Environmental Performance Improvements. Corporate Environmental Strategy. v. 9, n. 2, p. 183-192, 2002.

ARANTES, N. Sistemas de gestão empresarial: conceitos permanentes na administração de empresas válidas. S. Paulo: Atlas, 1998.

ASSOCIAÇÃO BRASILEIRA DE NORMAS TÉCNICAS ISO14031 - Gestão ambiental: Avaliação de desempenho ambiental - Diretrizes, 1999.

AZZONE, G.; MANZINI, R. Measuring strategic environmental performance. Business Strategy and the Environment. v. 3, n. 1, p. 1-14, 1994.

BANAI-KASHANI, R. A new method for site suitability analysis: The analytic hierarchy process. Environmental Management .v. 13, n. 6, p. 685-693, 1989.

BITITCI, U.; NUDURUPATI, S.; TURNER, T.; CREIGHTON, S. Web enable performance measurements: management implications. International Journal of Operations and Production Management, v. 22, n. 11, p. 1273-1287, 2002.

BOURNE, M.; MILLS, J.; WILCOX, M.; NEELY, A.; PLATTS, K. Designing, implementing and updating performance measurements systems. International Journal of Operations and Production Management, v. 20, n. 7, p. 754-771, 2000.
BOLLMANN, H. Indicadores Ambientais. In: MAIA, N.; MARTOS, H.; BARRELLA, W. (org.) Indicadores Ambientais: Conceitos e Aplicações. S. Paulo: EDUC/ COMPED/INEP, 2001.

CAMPOS, L. SGADA - Sistema de gestão e avaliação de desempenho ambiental: uma proposta de implementação. 2001. 220 p. Tese de doutorado. Engenharia de Produção e Sistemas, UFSC, Florianópolis.

CESARO, E. Impatto ambientale. In: LUCARELLI, F. (org.). Dal Mediterraneo per I'Amazzonia. Napoli: Editoriale Scientifica, 1992.

CHIOU, H.; TZENG, G. Fuzzy multiple-criteria decisionmaking approach for industrial green engineering. Environmental Management. v. 30, n. 6, p. 816-830, 2002.

CORNFORTH, I. Selecting indicators for assessing sustainable land management. Journal of Environmental Management. v. 56, n. 3, p. 173-179, 1999.

DIAS-SARDINHA, I.; REIJNDERS, L. Evaluating environmental and social performance of large Portuguese companies: a balanced scorecard approach. Business Strategy and the Environment. v. 14, n. 2, p. 73-91, 2005.

DIAS-SARDINHA, I.; REIJNDERS, L. Environmental performance evaluation and sustainability performance evaluation of organizations: an evolutionary framework. EcoManagement and Auditing. v. 8, n. 2, p. 71-79, 2001.

DONAIRE, D. Gestão Ambiental na Empresa. São Paulo: Atlas, 1999. 
ECOBLOCK. Disponível em: http://gasa.dcea.fct.unl.pt/ ecoblock, acesso em maio de 2006.

ENVIRONMENTAL PROTECTION AGENCY-EPA, 2004. Disponível em: <http://www.epa.gov>. Acesso em: 03 de maio de 2004.

FORMAN, E.; SELLY, M. (2001) Decisions by objectives. Expert Choice, Inc. Disponível em http://www.expertchoice.com, acesso em maio de 2004.

GASPARETTO, V. Proposta de uma sistemática para avaliação de desempenho em cadeias de suprimentos. 2003. 248 p. Tese (Doutorado em Engenharia de Produção). Engenharia de Produção e Sistemas, UFSC, Florianópolis.

GOMES, C.; YASIM, M.; LISBOA, J. An examination of manufacturing organizations's performance evaluation: analysis, implications and a framework for future research. International Journal of Operations and Production Management, v. 24, n. 5, p. 488-513, 2004.

GOUGH, J.; WARD, J. Environmental decision-making and lake management. Journal of Environmental Management. v. 48, n. 1, p. 1-15, 1996.

HAMMOND, A.; ADRANSE, A.; RODENBURG, E.; BRYANT, D.; WOODWARD, R. Environmental indicators: a systematic approach to measuring and reporting on environmental policy performance in the context of sustainable development, New York: World Resources Institute, 1995.

HOGARTH, R. Judgement and choice. John Wiley \& Sons, Essex, UK, 1988.

HRONEC, S. Vital signs: using quality, time, and cost performance measurements to chart your company's future. USA: Arthur Andersen Co.,1993.

KASUL, R.; MOTWANI, J. Performance measurements in world-class operations: a strategic model. Benchmarking for Quality Management and Technology, v. 2, n. 2, p. 20-36, 1995.

KEENEY, R.; RAIFFA, H.: Decisions with multiples objectives: preferences and value trade-offs, John Wiley and sons, New York, 1976.

LIU, F.; HAI, H. The voting analytic hierarchy process method for selecting supplier. International Journal of Production Economics, v. 97, p. 308-317, 2005.

LOHMAN, C.; FORTUIN, L.; WOUTERS, M. Designing a performance measurement system: a case study. European Journal of Operational Research, v. 156, n. 2, p. 267-286, 2004.

MACHADO, L. Qualidade Ambiental: indicadores quantitativos e perceptivos. In: MARTOS, H.; MAIA, N. (org.). Indicadores Ambientais. Sorocaba: Editora USP, 1997.
MAZARI-HIRIART, M.; CRUZ-BELLO, G.; BOJÓRQUEZ-TAPIA， L.; JUÁREZ-MARUSICH， L.; ALCANTAR-LÓPEZ, G.; MARÍN, L.; SOTO-GALERA, G. Groundwater Vulnerability Assessment for Organic Compounds: Fuzzy Multicriteria Approach for Mexico City. Environmental Management. v. 37, n. 3, p. 410-421, 2006

MELNICK, S.; STEWARD, D.; SWINK; M. Metrics and performance measurements in operations management: dealing with the metrics maze. Journal of Operations Management, 22, p. 219-217, 2004.

MELO, J.; PEGADO, C. Ecoblock: A method for integrated environmental performance evaluation of companies and products (construction case-study), 2006. Disponível em http://gasa.dcea.fct.unl.pt/ecoblock/EcoBalance_02.pdf. Acesso em: 03 de maio de 2006.

MIRANDA, L.; SILVA, J. Medição de desempenho. In: SCHMIDT, P. (org.). Controladoria: agregando valor para a empresa. Porto Alegre: Bookman, 2002.

MONTEIRO, P.; CASTRO, A.; PROCHNIK, V. A mensuração do desempenho ambiental no Balanced Scorecard e o caso da Shell. Anais do VII Encontro Nacional sobre Gestão Empresarial e Meio Ambiente, FGV/USP, 2003. Disponível em: http://www.ie.ufrj.br/cadeiasprodutivas/pdfs/a_mensuracao_do_desempenho_ambiental_no_balanced_scorecard_o_caso_da_shell_brasil.pdf. Acesso em 04 de maio de 2004.

MOREIRA, D. Dimensões do desempenho em manufatura e serviços, S. Paulo: Pioneira, 1996.

MÜLLER, C. Modelo de gestão integrando planejamento estratégico, sistema de avaliação de desempenho e gerenciamento de processo. 2003. 292 f. Tese (Doutorado em Engenharia de Produção). Escola de Engenharia, UFRGS, Porto Alegre.

OLSTHOORN, X.; TYTECA, D.; WEHRMEYER, W.; WAGNER, M. 2001, Environmental indicators for business: a review of the literature and standardisation methods. Journal of Cleaner Production. v. 9, p. 453-463.

PARTOVI, F.; WHITERS, B.; BRADFORD, J. How Tompkins rubber company used Analytic Hierarchy Process to enhance ISO-9000 related decision making, Production and Inventory Management Journal, v. 43, n. 1-2, first/second quarters, 2002.

PEARSON, J.; BARNES, T. Improve Environmental Performance Through Community Action. Eco-Management and Auditing. v. 6, p. 76-79, 1999.

PEGADO, C.; MELO J.; RAMOS, T. Ecoblock: Método de avaliação do desempenho ambiental, 2001. Disponível em: http://gasa.dcea.fct.unl.pt/ecoblock/Apea_01.pdf Acesso em: 03 de maio de 2006. 
PIRES, S. Gestão da cadeia de suprimentos (supplychain management): conceitos, estratégias, práticas e casos. S. Paulo: Atlas, 2004.

RAMOS, T.; MELO, J. Developing and implementing an environmental performance index for the portuguese military. Business Strategy and the Environment. v. 15, n. 2, p. 71-86, 2006.

RIBEIRO, J.; NEWMANN, C. Planejamento e condução de grupos focados. In: RIBEIRO, J. (org.) Grupos focados: teoria e aplicações. P. Alegre: FEENG-UFRGS-PPGEP, 2003.

ROESCH, S. Projetos de estágio e de pesquisa em administração: guia para estágios, trabalhos de conclusão, dissertações e estudos de caso. S. Paulo: Atlas, 1999.

ROSSETTO, A. Proposta de um sistema integrado de gestão do ambiente urbano (SIGAU) para o desenvolvimento sustentável de cidades. 2003. 404 f. Tese (Doutorado em Engenharia de Produção). Engenharia de Produção e Sistemas, UFSC, Florianópolis.

SAATY, T. Método de Análise Hierárquica. São Paulo: Makron Books, 1991.

SALOMON, V. Auxílio à decisão para a adoção de políticas de compras, Produto \& Produção, v. 6, n. 1, 2002.
SELLITTO, M.; RIBEIRO, J. Construção de indicadores para avaliação de conceitos intangíveis em sistemas produtivos. Gestão \& Produção. v. 11, n. 1, pág. 75-90, 2004.

SELLITTO, M. Medição e controle de desempenho estratégico em sistemas de manufatura. 2005. 195 f. Tese (Doutorado em Engenharia de Produção). Escola de Engenharia, UFRGS, Porto Alegre.

THORESEN, J. Environmental performance evaluation - a tool for industrial improvement. Journal of Cleaner Production. v. 7, p. 365-370, 1999.

TYTECA, D. On the Measurement of the Environmental Performance of Firms- A Literature Review and a Productive Efficiency Perspective. Journal of Environmental Management. v. 46, n. 3, p. 281-308, 1996.

TZIONAS, P.; IOANNIDOU, I.; PARASKEVOPOULOS, S. A Hierarchical Fuzzy Decision Support System for the Environmental Rehabilitation of Lake Koronia, Greece. Environmental Management. v. 34, n. 2, p. 245-260, 2004.

ZOBEL, T.; ALMROTH, C.; BRESKY, J.; BURMAN, J. Identification and assessment of environmental aspects in an EMS context: an approach to a new reproducible method based on LCA methodology Journal of Cleaner Production. v. 10, n. 4, p. 381-396, 2002.

\title{
ENVIRONMENTAL PERFORMANCE MEASUREMENT SUPPORTED BY A MULTICRITERIAL APPROACH: A CASE STUDY IN A MANUFACTURING OPERATION IN THE AUTOMOTIVE INDUSTRY
}

\begin{abstract}
This paper presents and discusses a case concerning environmental performance measurement (MDA), in which a multicriterial approach, the AHP, was used. The measurement took place in a manufacturing operation in the automotive industry, whose environmental management system (SGA) is certified according to ISO 14001: 2004. The methodology was developed in such a way that it is feasible to reproduce it in other industries or operations. The paper discusses business and environmental performance, justifying the need for a numerical index, in order to establish such performances. We propose the measurement methodology, in which we formulate hierarchical constructs for sustaining the index, weighed by the AHP and measured by indicators evaluated with historical data, available in the operation database. The index reached almost $85 \%$ of the maximum range. The measurement constructs are: solid wasting; effluent; natural resources; environmental management; and atmospheric emissions. The main improvement opportunities are: reduction in natural resources quantity requirement and atmospheric emissions.
\end{abstract}

Keywords: Environmental performance measurement, environment performance control, environment indicator, environmental strategy, environmental performance modelling. 